\title{
Laser Resurfacing
}

\author{
Joseph P. Janik, M.D.,' Jodi L. Markus, M.D., 1 Zeena Al-Dujaili, B.S., ${ }^{2}$ \\ and Ramsey F. Markus, M.D. ${ }^{1}$
}

In a society desiring images of beauty and youthfulness, the world of cutaneous surgery offers the gifts of facial rejuvenation for those determined to combat the signs of aging. With the development of novel laser and plasma technology, pigmentary changes, scarring, and wrinkles can be conquered providing smoother, healthier, younger-looking skin. This review highlights five of the most popular resurfacing technologies in practice today including the carbon dioxide $\left(\mathrm{CO}_{2}\right)$ laser, the erbium:yttrium-aluminum-garnet (Er:YAG) laser, combination resurfacing, fractional photothermolysis, and plasma resurfacing.

KEYWORDS: Laser resurfacing, $\mathrm{CO}_{2}$ laser, Er:YAG laser, Fraxel ${ }^{\mathrm{TM}}$ laser, plasma resurfacing

Laser technology used in medicine today has traveled a long way since the development of the ruby laser in 1960 and the $\mathrm{CO}_{2}$ laser in 1964. Over the past 40 years, theories like selective photothermolysis have been applied and many different technologies developed. ${ }^{1}$ Fueled by the public's ever-increasing demand for cosmetic surgery procedures and products, many new laser devices can be found in the marketplace claiming to treat everything from rhytides to skin cancer. When confronted with the decision on what lasers to purchase for a practice and how to use them, it can be very confusing. The purpose of this review article is to give a clinical background on five different resurfacing technologies including the carbon dioxide $\left(\mathrm{CO}_{2}\right)$ laser, the erbium:yttrium-aluminum-garnet (Er:YAG) laser, the combined Er:YAG/CO $\mathrm{CO}_{2}$ dual-mode laser system, fractional photothermolysis, and plasma resurfacing.

\section{CARBON DIOXIDE LASER}

The mainstay for skin resurfacing over the past few decades has been the $\mathrm{CO}_{2}$ laser. Developed in the 1960s and implemented in the 1980s, the $\mathrm{CO}_{2}$ laser has largely replaced the more unpredictable and potentially dangerous deep phenol peel and mechanical abrasion. ${ }^{2}$ The $\mathrm{CO}_{2}$ laser accurately vaporizes the epidermis and dermis layer by layer resulting in the reorganization and strengthening of collagen bundles in addition to epidermal regeneration to rejuvenate the skin. The first $\mathrm{CO}_{2}$ lasers developed used a continuous wave; however, this technique was not adopted widely because of the significant thermal damage and the resultant high potential of scarring. The advent of short-pulsed highenergy and scanned carbon dioxide lasers that limit skin heating revolutionized the resurfacing industry.

These new lasers are capable of removing layers of photodamaged skin in a precise fashion, leaving only a narrow zone of thermal necrosis. The first laser pass significantly ablates more tissue than the second or subsequent passes, and an ablation plateau is reached in three to four passes, limiting depth to $\sim 250 \mu \mathrm{m}$. ${ }^{3}$ The ability to control the epidermal vaporization depth with minimal damage to the papillary dermis is a prerequisite for successful, scorch-free skin resurfacing. ${ }^{4}$ The $\mathrm{CO}_{2}$

\footnotetext{
${ }^{1}$ Department of Dermatology, Baylor College of Medicine, Houston, Texas; ${ }^{2}$ Tulane University School of Medicine, Lafayette, Louisiana. Address for correspondence and reprint requests: Ramsey F. Markus, M.D., Assistant Professor of Dermatology, Baylor Dermatology, 6620 Main St., Suite 1425, Houston, TX 77030
}

Lasers in Plastic Surgery; Guest Editor, Ramsey F. Markus, M.D.

Semin Plast Surg 2007;21:139-146. Copyright (C) 2007 by Thieme Medical Publishers, Inc., 333 Seventh Avenue, New York, NY 10001, USA. Tel: +1(212) 584-4662.

DOI 10.1055/s-2007-991182. ISSN 1535-2188. 
laser achieves the desired results by removing the outermost layer of the epidermis and some portion of the superficial dermis and then reestablishing this layer through normal wound healing. Healthy epidermis migrates from adjacent tissue and adnexal structures, and new collagen and elastic tissue are deposited by activated fibroblasts. ${ }^{5}$ To respond to these requirements and achieve well-controlled tissue ablation without the risks of scarring or dyspigmentation, it is important, according to the theory of selective photothermolysis, to confine ablation to a thin layer (20 to $50 \mu \mathrm{m}$ ) and deliver enough energy to vaporize tissue $\left(5 \mathrm{~J} / \mathrm{cm}^{2}\right)$ in a time shorter than the thermal relaxation time of the skin (1 millisecond). Wound remodeling then continues for 6 to 18 months. ${ }^{6}$

$\mathrm{CO}_{2}$ lasers emit light at a wavelength of $10,600 \mathrm{~nm}$ that is absorbed strongly by water (the primary chromophore for carbon dioxide light that is abundant in skin). Conversion of radiant energy to heat at the point of absorption instantly raises the temperature of tissue water to more than $100^{\circ} \mathrm{C}$, so that the tissue water vaporizes. The threshold for vaporization of human skin is $\sim 5 \mathrm{~J} / \mathrm{cm}^{2}$ with the $\mathrm{CO}_{2}$ laser. Thermal diffusion will be confined if the laser pulse-width is less than the thermal relaxation time of the tissue $(1 \text { millisecond })^{3}$ Thus, with $\mathrm{CO}_{2}$ resurfacing lasers, if the pulse width is less than 1 millisecond, minimal thermal necrosis will result. This zone of thermal necrosis is sufficient to seal small dermal blood vessels and lymphatics, yet narrow enough to reduce the incidence of scarring. ${ }^{5}$

Two different types of $\mathrm{CO}_{2}$ lasers are promoted for the purpose of skin resurfacing. The first is a highpower, pulsed $\mathrm{CO}_{2}$ laser that can deliver a treatment fluence of 5 to $7 \mathrm{~J} / \mathrm{cm}^{2}$ with each submillisecond pulse. Additionally, some of these systems have a computerized pattern generator that rapidly and precisely places small, individual laser pulses in several different arrangements. ${ }^{4}$ The second uses an optomechanical flash scanner connected to a conventional continuouswave $\mathrm{CO}_{2}$ laser. This scanner efficiently distributes continuous-wave laser energy so that dwell time is shorter than skin thermal relaxation time, thus mimicking truly pulsed $\mathrm{CO}_{2}$ lasers. ${ }^{4}$ Later, $\mathrm{CO}_{2}$ resurfacing lasers with very short pulse durations (60 microseconds) emerged; they ablate less tissue per pass and leave behind a narrower zone of thermal necrosis than the original $\mathrm{CO}_{2}$ resurfacing lasers. These newer laser systems allow epidermal vaporization with minimal thermal damage to the papillary dermis. ${ }^{7}$ The newer superpulsed lasers have pulse energies 5 to 7 times higher than conventional superpulsed lasers to maximize tissue vaporization, as well as a pulse duration of less than 1 millisecond, following the principles of selective photothermolysis. This results in pure steam vaporization with minimal thermal injury diffusing into adjacent tissue. ${ }^{8,9}$

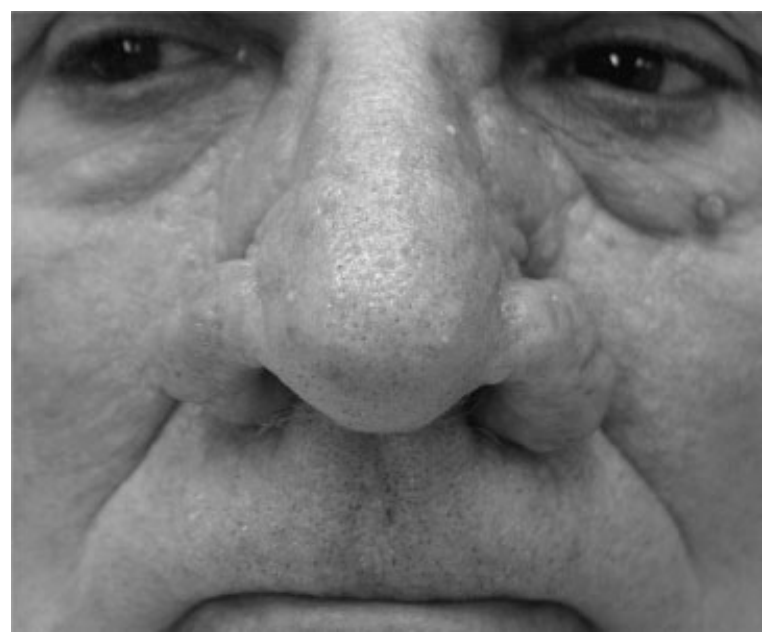

Figure 1 Bilateral alar regions, rhinophymatous changes before treatment.

As with other resurfacing modalities such as chemical peeling and dermabrasion, $\mathrm{CO}_{2}$ lasers completely remove the epidermis and part of the dermis resulting in wound remodeling with subsequent new collagen and elastin fiber formation that translates into firmer, tighter skin (Figs. 1, 2, and 3) ${ }^{10}$ Histopathologic studies show that the depths of ablation are 20 to $30 \mu \mathrm{m}$ and 30 to $50 \mu \mathrm{m}$ after one pass using pulsed and scanning laser technology, respectively. The residual thermal damage is 20 to $40 \mu \mathrm{m}$ per pass, which does not increase to more than $150 \mu \mathrm{m}$ on the third pass. The thermal damage produced by the newer $\mathrm{CO}_{2}$ lasers can be controlled by varying the pulse duration, which makes the treatment safer, more reproducible, and more predictable.

Similar to other resurfacing modalities, incidence of complications after $\mathrm{CO}_{2}$ laser resurfacing primarily is related to depth attained. One of the most common expected complications encountered is postresurfacing swelling. It peaks at about 2 to 3 days and usually subsides at 1 week. Intravenous betamethasone intraoperatively

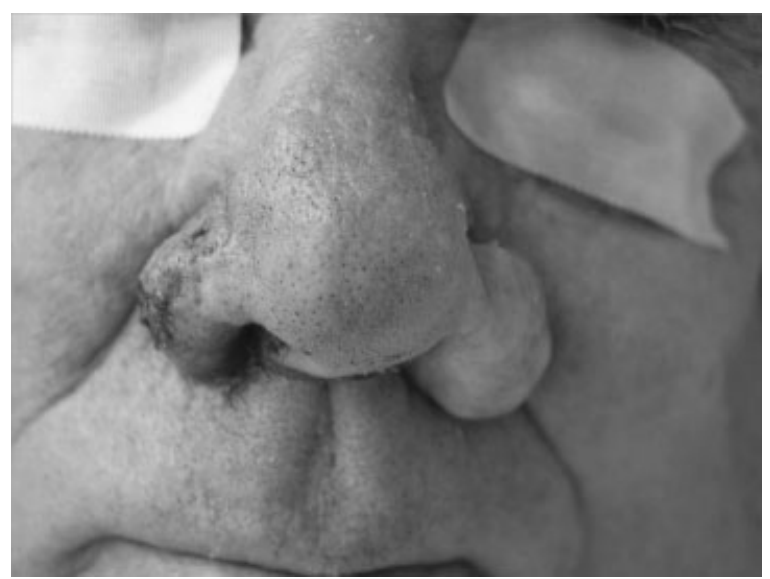

Figure 2 Right ala, status immediately after treatment with combination scalpel and continuous $\mathrm{CO}_{2}$ laser resurfacing. 


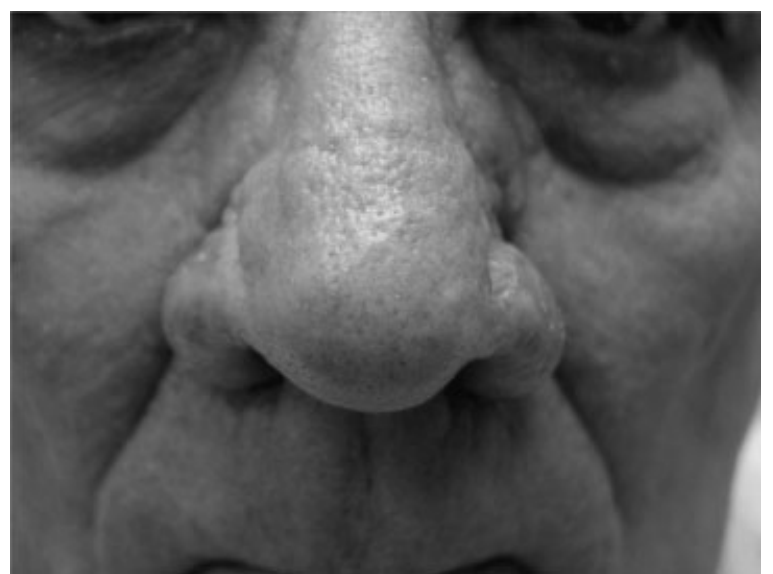

Figure 3 Bilateral alar regions, status after treatment with combination scalpel and continuous $\mathrm{CO}_{2}$ laser resurfacing.

and a course of oral prednisone postoperatively for 5 days can help significantly in decreasing the swelling. ${ }^{11}$ Erythema, to some degree, is observed in all patients. It is related to increased blood flow, collagen remodeling, inflammation, and increased metabolic activity. Pruritus is also common after laser resurfacing, yet it may signal infection, contact dermatitis, or early scarring. In the absence of these conditions, pruritus responds to an oral antihistamine. ${ }^{12}$ Milia and acne can be observed 2 to 3 days postoperatively and are partially related to the use of occlusive ointments. Many of these patients are acne prone prior to treatment, and their condition can be improved significantly by reintroducing topical retinoic acid and topical antibiotics to their postresurfacing regimen. ${ }^{11}$ Postinflammatory hyperpigmentation tends to occur 2 to 3 weeks after therapy, especially in patients with dark skin. Preconditioning the skin with retinoic acid and hydroquinone prior to $\mathrm{CO}_{2}$ resurfacing may decrease incidence, severity, and duration of this phenomenon, and aggressive postresurfacing skin reconditioning using hydroquinone 2 to $4 \%$ twice per day, retinoic acid ( 0.5 to $0.1 \%$ ) at bedtime, and sun protection and sunscreen can hasten resolution in as early as 4 weeks. ${ }^{4}$

Unexpected complications associated with $\mathrm{CO}_{2}$ laser resurfacing include infection (bacterial, viral, yeast, fungal). A typical presentation is a papulopustular eruption with itching or pain and delayed healing. Irritant or allergic contact dermatitis can also occur secondary to topical antibiotics (e.g., neomycin, bacitracin). ${ }^{11} \mathrm{Hypo}^{-}$ pigmentation in darker-skinned individuals can be a risk, which increases with increased depth of laser penetration and can be disguised with total facial treatment as opposed to regional therapy. ${ }^{12}$ Additional unexpected complications include sharp demarcation lines, which can be avoided by creating a transitional zone of resurfaced skin (i.e., gradual change in depth of resurfacing between face and neck) and combining full-face resurfacing with a light chemical peel such as a TCA peel on the neck to create a less noticeable gradient zone between resurfaced face and neck/chest. ${ }^{11}$ Development of hypertrophic scars and keloids can occur and are related to the depth of resurfacing achieved, development of infection, postoperative wound care, genetic predisposition, and treatment of nonfacial areas. ${ }^{3}$ Ectropion of the lower eyelid has also been reported and is usually the result of an overaggressive treatment, a preexisting laxity, activation of a previous blepharoplasty scar, or development of an infection. It can be avoided by testing the lid for laxity before resurfacing, by limiting the depth of resurfacing to the papillary dermis, and by decreasing the power settings. ${ }^{11}$ Tooth enamel and corneal damage can occur but are easily avoided if proper protection is utilized including metal shields coated with copious lubricants. ${ }^{11,12}$ In the hands of an experienced operator, the $\mathrm{CO}_{2}$ laser can work wonders for resurfacing the skin, but if improperly handled, serious complications will occur.

\section{ERBIUM:YTTRIUM-ALUMINUM-GARNET LASER}

In the 1990s, the first Er:YAG lasers were introduced for the resurfacing of photodamaged skin. Currently, there are more than 30 different brands of Er:YAG lasers available. These lasers vary greatly in spot size, power, speed, and availability of scanners. The wavelength of the Er:YAG laser is $2940 \mathrm{~nm}$, and its chromophore is water.

The major innovation of the Er:YAG laser over the $\mathrm{CO}_{2}$ laser is its shorter wavelength, which increases its absorption coefficient through water 10 - to 16 -fold. ${ }^{13}$ During the past decade, more advances have been made with the Er:YAG system. The first version of the Er:YAG laser had pulse lengths in the range of 25 to 300 microseconds, producing ablation without necrosis. ${ }^{14}$ Modifications were made including prolonging pulse length or subablative low-fluence pulses after each ablative pulse to allow for a coagulation mode as well as an ablative mode. ${ }^{15}$

In general, a single pulse of the Er:YAG laser at $5 \mathrm{~J} / \mathrm{cm}^{2}$ will ablate 20 to $25 \mu \mathrm{m}$ of tissue. ${ }^{16}$ There will also be a 5- to $10-\mu \mathrm{m}$ zone of thermal necrosis at the treatment site. ${ }^{16}$ As mentioned previously, scanners are available to expedite the procedure with certain Er:YAG models but are not essential. They are not essential because pulse stacking or overlapping of the Er:YAG laser during treatment has not been shown to cause additional necrosis, in contrast with the $\mathrm{CO}_{2}$ laser. $^{16}$

Er:YAG lasers have been used to treat many aspects of photoaged skin including actinic keratoses, solar lentigines, superficial rhytides, mild dyschromia, and Favre-Racouchot disease. ${ }^{17}$ Other potential targets include colloid milium, angiofibromas, nevi, seborrheic 
keratosis, xanthelasma, syringomas, sebaceous hyperplasia, rhinophyma, atrophic facial acne scars, atrophic discoid lupus scars, trichoepitheliomas, actinic cheilitis, Bowen's disease, erythroplasia of Queyrat, and laserassisted hair grafting in androgenic alopecia. ${ }^{16,18}$ Additionally, it has been used in combination with topical 5-fluorouracil to treat keratoacanthomas and superficial basal cell carcinomas. ${ }^{18}$

The risks of side effects from the Er:YAG laser are dependent upon the location being treated and the depth of skin removal. ${ }^{16}$ The common, predictable, and immediate side effects, which last several days after laser therapy, include pain, swelling, pruritus, oozing, crusting, and erythema. The intraoperative pain is managed on an individual treatment basis. Very small lesions like seborrheic keratosis may be treated without anesthesia. Superficial peeling treatments sometimes only require topical anesthetic mixtures like lidocaine and prilocaine. When deeper and larger procedures are done, local and even general anesthesia may be required for the procedure. The most common adverse side effect is pigmentary change, which is usually temporary and considered postinflammatory.

Unexpected side effects and complications include permanent hyper- or hypopigmentation, eczema, impaired healing, scars, infections, persistent erythema, milia, and acneiform eruptions. Pigmentary complications are more common in darker-skinned individuals, and therefore, patient selection is of the utmost importance in preventing unruly side effects. Postoperative infections are the same as for any surgical procedure and include bacterial, viral, and fungal infections. Clean treatment environments are recommended, as well as giving herpes simplex virus prophylaxis in high-risk individuals.

\section{COMBINED ERBIUM:YAG/CO 2 DUAL-MODE LASER SYSTEM}

As previously mentioned, the $\mathrm{CO}_{2}$ laser has a wavelength of 10,600 nm, and the Er:YAG laser has a wavelength of $2940 \mathrm{~nm}$. Although they have vastly different wavelengths, both are resurfacing lasers and both target the same chromophore: water. The Er:YAG laser's affinity for water is 10 - to 16 -fold greater than the $\mathrm{CO}_{2}$ laser's affinity, and therefore, the Er:YAG laser causes less heat injury, has more depth control, and has less risk of causing permanent scarring and pigmentary changes. ${ }^{13}$

Thus, why would anyone want to combine these two lasers for a resurfacing procedure? Some cutaneous surgeons have preferentially taken the approach of combining an ablative Er:YAG laser with a vaporizing pulsed $\mathrm{CO}_{2}$ laser to facilitate clean surface etching by Er:YAG ablation and permitting additional coagulation by $\mathrm{CO}_{2}$ laser pulses when required, or to add Er:YAG pulses subsequent to $\mathrm{CO}_{2}$ laser resurfacing to remove excessive surface necrosis. ${ }^{19}$ By using the two lasers

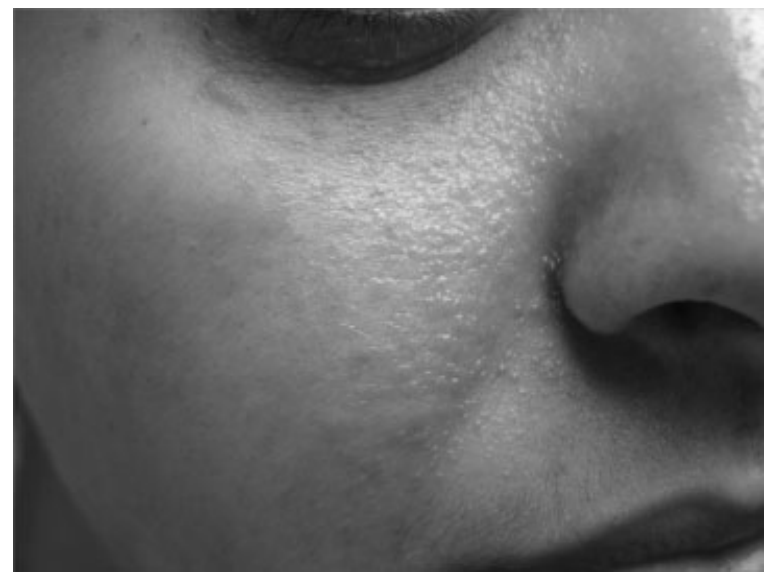

Figure 4 Right cheek, angiofibromas before treatment.

together, one can "fine tune" the resurfacing procedure by utilizing different wavelengths, different depths of penetration, and different surface necrosis that are required to give a uniform treatment to different areas on the head and neck, which have variable thickness, color, and regenerative capabilities and require different resurfacing wavelengths for optimum results. Two laser systems that combine erbium $/ \mathrm{CO}_{2}$ capabilities are the Sciton Contour (Palo Alto, CA) and the Derma K (Lumenis. Santa Clara, CA) (Figs. 4 and 5).

\section{FRACTIONAL PHOTOTHERMOLYSIS}

Fractional photothermolysis was developed and released by Reliant Technologies (Mountain View, CA) in 2004, and given the brand name Fraxel ${ }^{\mathrm{TM}}{ }^{20}$ It is one of the newest technologies used for skin resurfacing. The wavelength of the laser is estimated to be $1550 \mathrm{~nm}$, and its chromophore is water. $^{21}$

The major innovation of the Fraxel laser is its unique delivery of energy into the aqueous tissue. Prior

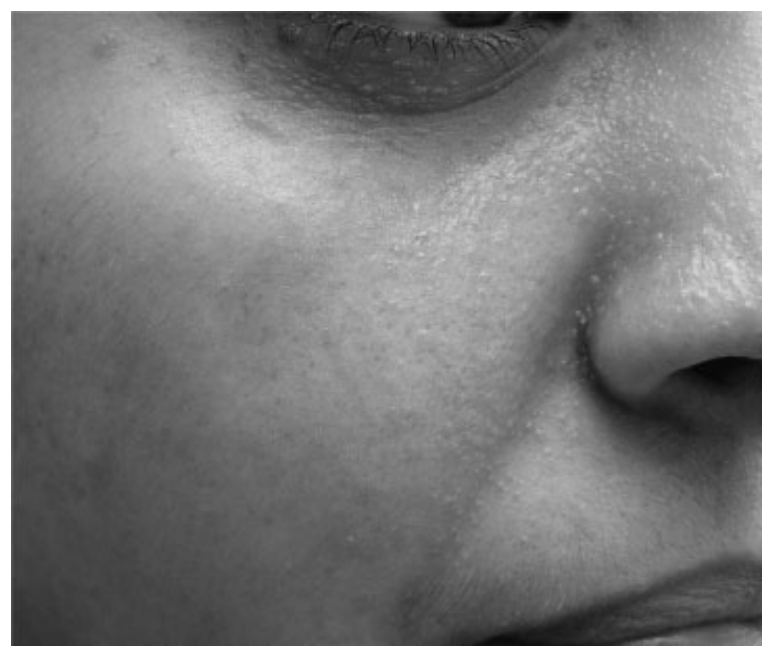

Figure 5 Right cheek, angiofibromas after treatment with Sciton's Contour laser. 
to laser use, a blue dye is applied to the patient's skin. This dye does not react to the laser but gives the contrast necessary to allow the revolutionary computer guidance system to track the movement of the hand piece and evenly deliver and distribute from 150 to 250 microthermal wounds $/ \mathrm{cm}^{2}$. The diameter of these microthermal zones ranges from 30 to $70 \mu \mathrm{m}$, and the depth of penetration into the epidermis and dermis is 400 to $700 \mu \mathrm{m} .{ }^{20}$ The densities utilized with this laser in current studies and practice have ranged from 400 to 4000 microthermal zones $/ \mathrm{cm}^{2}{ }^{22}$ These variations in densities are achieved in part by increasing or decreasing the number of times the laser is passed over the surface of the skin being treated.

By creating microzones of thermal damage surrounded by zones of normal tissue, the Fraxel laser is believed to cause an optimum balance between selective skin photothermolysis and wound regenerative capacity. This balance allows for maximum skin remodeling to occur with minimal postoperative downtime. Recent clinical and histologic studies done on the skin after Fraxel therapy revealed complete re-epithelialization within 1 day and enhanced undulating rete ridges and increased mucin deposition within the superficial dermis after 3 months. ${ }^{23}$ Patients are usually scheduled for Fraxel therapy every 2 to 4 weeks for a total of three to five sessions. Several months after completion of the last treatment, improvements in cutaneous texture, pigmentation, and scarring can be seen. ${ }^{20}$

To date, fractional photothermolysis has been approved by the U.S. Food and Drug Administration (FDA) for the treatment of pigmented skin lesions, periorbital rhytides, skin resurfacing, melasma, and soft tissue coagulation. ${ }^{22}$ Fraxel therapy has also been reported to help with "ice-pick," "boxcar," and "rolling" acne scars in a limited number of patients, as well as solar lentigines (Figs. 6 and 7). ${ }^{20,21}$ On an anecdotal basis, Fraxel has been safe to use on areas other than the face, in contrast with some of the older ablative resurfacing

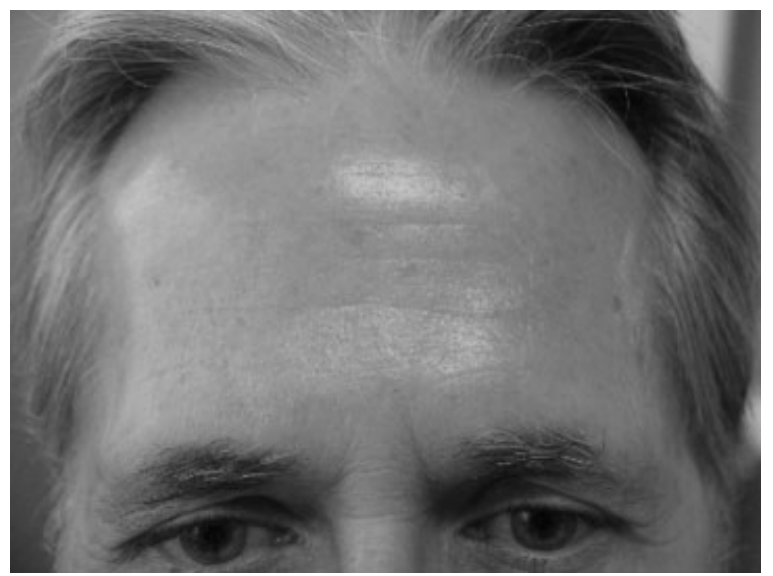

Figure 6 Forehead, wrinkles and actinic damage before treatment.

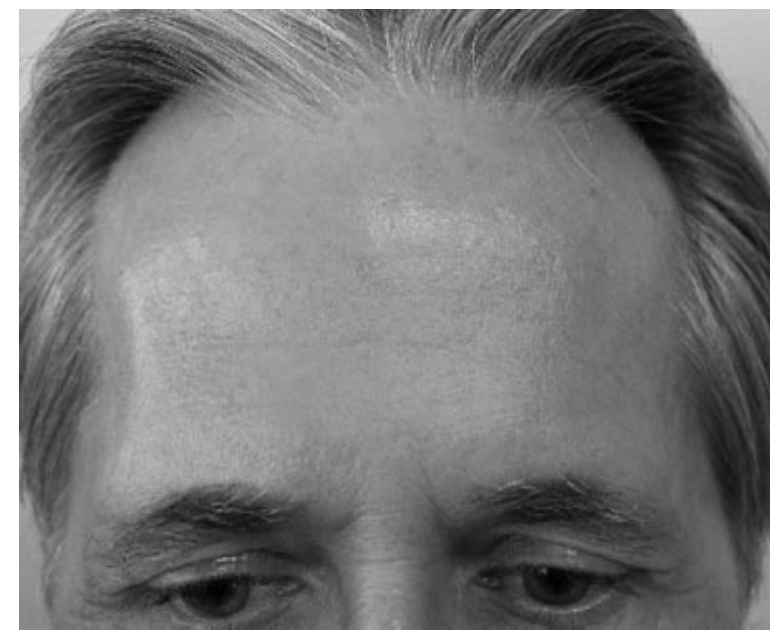

Figure 7 Forehead, status after three Fraxel sessions.

lasers that can cause significant scarring and permanent pigmentary changes when used on nonfacial areas of the skin. ${ }^{23}$

The common short-term side effects of the Fraxel laser include postoperative erythema, minimal facial swelling, xerosis, scaling, pruritus, mild superficial scratches secondary to the hand piece, and bronzing. ${ }^{22}$ Treatment discomfort is also associated in all cases; however, the pain is usually minimized with preoperative topical anesthetic ointment and intraoperative forced-air cooling. The xerosis and dryness of the skin that occurs postoperatively is easily managed with the application of moisturizers on a twice-daily basis, and the superficial scratches that previously occurred when using the older-model hand pieces have decreased significantly with use of the newer models. ${ }^{22}$ Most patients can return to work within 2 to 3 days.

Unexpected and long-term complications of Fraxel therapy have not been reported on a widespread basis at this time. Herpes simplex activation has been seen, which may require preoperative therapy in certain candidates. ${ }^{22}$ Permanent scarring and/or hypopigmentation have not been recorded. Thus far, the Fraxel laser has demonstrated an excellent combination of safety and effectiveness.

While the Fraxel laser system is the gold standard for this new technology, three other companies have developed competing laser systems that also take advantage of the concept of fractional photothermolysis. These lasers include Alma's Pixel (Caesarea, Israel) 2940-nm laser, Palomar's Lux (Burlington, MA) 1540-nm laser, and Cynosure's Affirm (Westford, MA) 1440-nm laser. Unfortunately, publicized data are unavailable to compare and contrast the efficacy and side-effect profiles at this time.

\section{PLASMA RESURFACING}

The Plasma Skin Regeneration (PSR) system launched in February 2005 by Rhytec Ltd (Waltham, MA) as the Portrait PSR device at the American Academy of 
Dermatology meeting is not light-based or radiofrequency $(\mathrm{RF})$. Rather, energy is delivered to the skin surface via nitrogen plasma. Plasma is the fourth state of matter in which electrons are stripped from atoms to form an ionized gas. ${ }^{24}$ Pulses of ultrahigh-frequency (UHF) RF energy are used to ionize a flow of nitrogen gas, producing millisecond pulses of plasma, with no UHF energy delivered to the skin. The plasma is characterized by a lilac glow transitioning to a yellowish light known as a Lewis-Rayleigh afterglow. This glow is directed, in pulses, through a quartz nozzle held $5 \mathrm{~mm}$ from the skin's surface, delivering energy through a 6-mm spot size. Upon impact, the ionized energy is released, causing a localized heating in a controlled, uniform manner without relying on a chromophore mediator. With no target chromophore, the disruptive effect of energy conversion seen when working with high-energy lasers is avoided. The result is a uniform and efficient distribution of energy into the dermis.
An important clinical reason for using nitrogen is that it purges oxygen from the skin's surface, so that oxidative carbonization is minimized, eliminating unpredictable hot spots and charring that can produce scarring. The presence of inert nitrogen flowing after the delivery of plasma, combined with the thermal relaxation between pulses, preserves the treated epidermis, thus providing a microenvironment for skin regeneration. The depth of the effect can be varied from superficial epidermis to deep dermis, similar to a $\mathrm{CO}_{2}$ laser, but without vaporization of tissue. The energy can be adjusted from 1 to $4 \mathrm{~J}$ per pulse. It is delivered like an airbrush, without contact, applying a series of non-overlapping pulses. Treatment is usually performed under topical anesthesia, but for higher-energy settings, adjunctive oral analgesia is recommended.

One unique feature of plasma resurfacing is its nonablative nature. Immediately postprocedure, the stratum corneum and epidermis are retained.

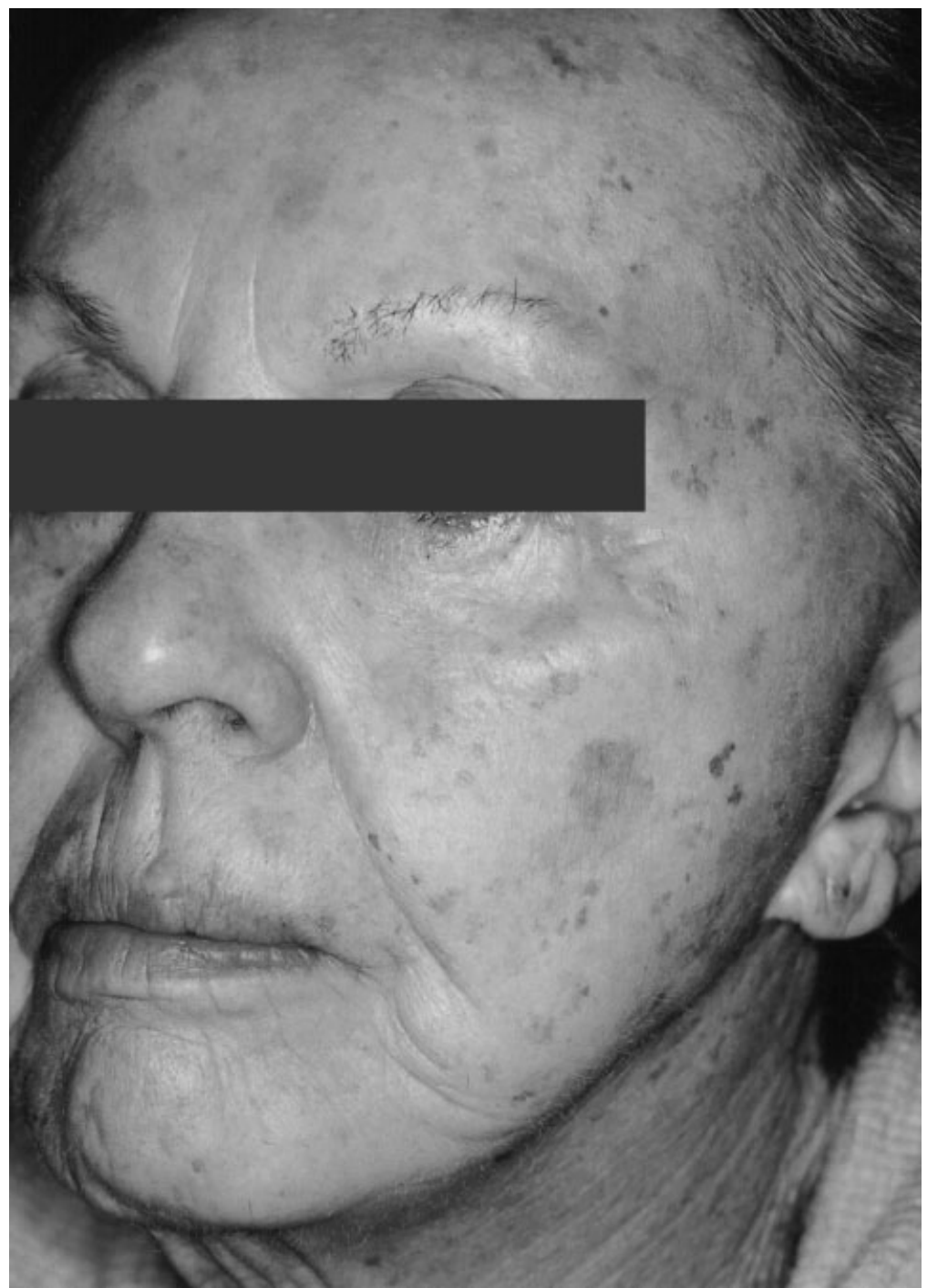

Figure 8 Left face, aged skin before treatment. 


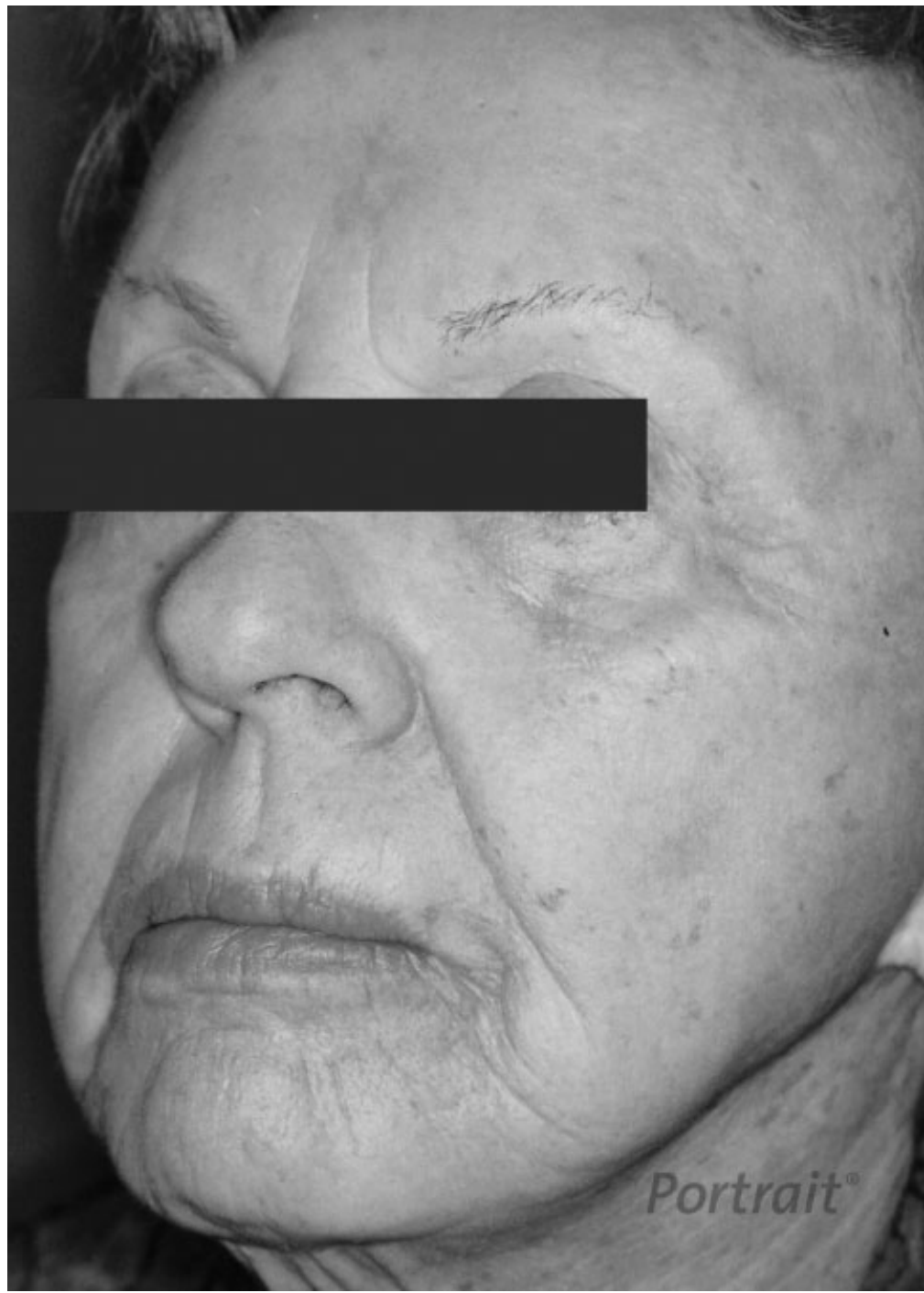

Figure 9 Left face, status 3 weeks after treatment with Rhytec's Portrait PSR system.

Preliminary studies comparing biopsies from $\mathrm{CO}_{2}$ laser-treated skin with PSR-treated skin show that tissue regeneration was much faster with PSR. ${ }^{25}$ In fact, in the PSR group, by the time the injured epidermis was ready to slough off, there was already a new epidermis forming beneath. These initial studies have led to the idea that there is no open wound period after PSR therapy and that the epidermis essentially acts as a natural biological dressing facilitating quick healing when doing plasma resurfacing. ${ }^{25}$

Plasma resurfacing is approved by the FDA for the treatment of facial rhytides, actinic keratosis, and benign skin lesions (Figs. 8 and 9). It has also been used to improve skin tone, texture, and pigmentation. Operators of plasma resurfacing machines also claim to see immediate posttreatment skin contraction in areas of lose, saggy skin, as well as continued improvement of all of the benefits listed above with subsequent treatments.
The expected side effects from plasma resurfacing thus far are minimal. The most common side effect is postoperative erythema, which usually subsides by day 3 . In essence, by postoperative day 4 , a new epidermis has formed, and by day 10, fibroblasts are increased and the tissue remodeling cascade has started. Isolated cases of hypopigmentation and hyperpigmentation have been noted, but no reported cases of patients with permanent pigmentary complications have been published. Currently, plasma resurfacing appears to be a very safe technology; however, long-term follow-up data are not available.

\section{CONCLUSION}

Laser resurfacing technology has come a long way since its first implementation in the 1980s. Driven by the public's ever-increasing demand to continue to look youthful, the newer versions of the $\mathrm{CO}_{2}$ and Er:YAG 
lasers, as well as the Fraxel and plasma technologies, strive to decrease side effects and increase therapeutic results. These inventions are a small but vital piece of the cosmetic surgeon's facial rejuvenation armamentarium.

\section{REFERENCES}

1. Anderson RR, Parrish JA. Selective photothermolysis: precise microsurgery by selective absorption of pulsed radiation. Science 1983;220:524-527

2. Fitzpatrick RE, Tope WD, Goldman MP, et al. Pulsed carbon dioxide laser, trichloroacetic acid, Baker-Gordon phenol, and dermabrasion: a comparative clinical and histologic study of cutaneous resurfacing in a porcine model. Arch Dermatol 1996;132:69-471

3. Fitzpatrick RE. Maximizing benefits and minimizing risk with $\mathrm{CO}_{2}$ laser resurfacing. Dermatol Clin 2002;20:77-86

4. Papadavid E, Katsambas A. Lasers for facial rejuvenation: a review. Int J Dermatol 2003;42:480-487

5. Kauvar ANB, Geronemus RG. Histology of laser resurfacing. Dermatol Clin 1997;15:459-467

6. Goldman MP, Fitzpatrick RE. Cutaneous Laser Surgery. The Art and Science of Selective Photothermolysis. St. Louis, MO: Mosby-Year Book; 1994:198-258

7. Alster TS, Nanni CA, Williams CM. Comparison of four carbon dioxide resurfacing lasers: a clinical and histopathologic evaluation. Dermatol Surg 1999;25:153-159

8. Fitzpatrick RE, Smith SR, Sriprachya-anunt S. Depth of vaporization and the effect of pulse stacking with the UltraPulse $\mathrm{CO}_{2}$ laser. J Am Acad Dermatol 1999;40:615622

9. Bernstein LJ, Kauvar ANB, Grossman M, Geronemus RG. Scar resurfacing with high-energy, short-pulsed and flashscanning carbon dioxide lasers. Dermatol Surg 1998;24:101-107

10. Ross EV, McKinlay JR, Anderson RR. Why does carbon dioxide resurfacing work?. Arch Dermatol 1999;135:444-454

11. Nanni CA, Alster TS. Complications of cutaneous laser surgery. Dermatol Surg 1998;24:209-219
12. Nanni CA, Alster TS. Complications of carbon dioxide laser resurfacing: an evaluation of 500 patients. Lasers Surg Med 1997;20:53-58

13. Kaufmann R, Hartmann A, Hibst R. Cutting and skinablative properties of pulsed mid-infrared laser surgery. J Dermatol Surg Oncol 1994;20:112-118

14. Hibst R, Kaufmann R. Effects of laser parameters on pulsed erbium:YAG laser skin ablation. Lasers Med Sci 1991;6:391397

15. Zachary CB. Modulating the Er:YAG laser. Lasers Surg Med 2000;26:223-226

16. Kaufmann R. Role of erbium:YAG laser in the treatment of aged skin. Clin Exp Dermatol 2001;26:631-636

17. Avram DK, Goldman MP. The safety and effectiveness of single-pass erbium:YAG laser in the treatment of mild to moderate photodamage. Dermatol Surg 2004;30:1073-1076

18. Tremblay JF, Carey W. Atrophic facial scars secondary to discoid lupus erythematous: treatment using the erbium: YAG laser. Dermatol Surg 2001;27:675-677

19. Goldman MP, Marchell N, Fitzpatrick RE. Laser skin resurfacing of the face with a combined $\mathrm{CO}_{2}$ /Er:YAG laser. Dermatol Surg 2000;26:102-104

20. Hamilton MM, Hobgood T. Emerging trends and techniques in male aesthetic surgery. Facial Plast Surg 2005;21: 324-327

21. Laubach HJ, Tannous Z, Anderson RR, Manstein D. Skin responses to fractional photothermolysis. Lasers Surg Med 2006;38:142-149

22. Geronemus RG. Fractional photothermolysis: current and future applications. Lasers Surg Med 2006;38:169-176

23. Manstein D, Herron GS, Sink RK, Tanner H, Anderson RR. Fractional photothermolysis: a new concept for cutaneous remodeling using microscopic patterns of thermal injury. Lasers Surg Med 2004;34:426-438

24. Bogle MA, Arndt KA, Dover JS. Evaluation of plasma skin regeneration technology in low fluence full-facial rejuvenation. Arch Dermatol 2007;143(2):168-174

25. Kilmer SL, Weiss RA, Geronemus RG, et al. Ablative vs nonablative skin rejuvenation: is there a middle ground?. Skin Aging Suppl 2006;Jan:21-24 